\title{
HIGHLY EFFICIENT AND VERSATILE ACETYLATION OF ALCOHOLS, PHENOLS AND AMINES CATALYZED BY METHYLENEDIPHOSPHONIC ACID (MDP) UNDER SOLVENT-FREE CONDITIONS
}

\author{
MINHAO XIE*, HONGYONG WANG, JUN WU, YONGJUN HE, YALING LIU, PEI ZOU \\ *Jiangsu Institute of Nuclear Medicine, Wuxi, 214063, P. R. China \\ (Received: March 1, 2011 - Accepted: July 12, 2011)
}

\begin{abstract}
Methylenediphosphonic Acid (MDP) was found to be a simple, cheap and reusable heterogeneous catalyst for the acetylation of structurally diverse alcohols, phenols and amines with acetic anhydride under solvent-free conditions at room temperature. This method showed preferential selectivity for the acetylation of the amino group in the presence of hydroxyl group. The method is very mild and the yields were in excellent.
\end{abstract}

Keywords: Bisphosphonic acid, MDP, Solvent-free, Acetylation.

\section{INTRODUCTION}

With increasing environmental concerns and the regulatory constraints faced in the synthesis of valuable industrial and pharmaceutical compounds, the development of new synthetic methods and reactions using new and environmental friendly reagents is becoming more attractive. The acetylation of alcohols is an important and E-mail: xiemh0704@sina.com Fax number: +086 51085513113 frequently used transformation in organic synthesis 1. The most commonly used reagent combination for this reaction uses an acid anhydride in the presence of an acid or base catalyst ${ }^{2}$. The various catalysts developed for acetylation include the use of $\mathrm{Bu}_{3} \mathrm{P}^{3}$, metal triflates such as Sc(OTf $)_{3}{ }^{4}, \mathrm{TMSOTf}^{5}, \mathrm{Sc}\left(\mathrm{NTf}_{2}\right)_{3}{ }^{6}, \mathrm{Cu}(\mathrm{OTf})_{2}{ }^{7}, \mathrm{In}(\mathrm{OTf})_{3}{ }^{8}, \mathrm{Bi}(\mathrm{OTf})_{3}{ }^{9}$, $\mathrm{ZrO}(\mathrm{OTf})_{2}{ }^{10} ; p$-toluenesulfonic acid ${ }^{11}$, Nafion- $\mathrm{H}^{12}$, Montmorillonite $\mathrm{K}-10$ and KSF clay ${ }^{13}$, yttria-zirconia ${ }^{14}$, NBS ${ }^{15}$, Zeolites ${ }^{16}$, 3 -nitrobenzeneboronic acid ${ }^{17}, \mathrm{La}\left(\mathrm{NO}_{3}\right)_{3}{ }^{18},\left(\mathrm{NH}_{4}\right)_{2.5} \mathrm{H}_{0.5} \mathrm{PW}_{12} \mathrm{O}_{40}{ }^{19}, \mathrm{H}_{5} \mathrm{PV}_{2} \mathrm{~W}_{10} \mathrm{O}_{40}{ }^{20}$ and molecular iodine ${ }^{21}$. The catalysts suffer from certain drawbacks. They are rather expensive or moisture sensitive. Nevertheless, there is still a great demand for acid catalysts to generate esters under mild conditions.

Bisphosphonic acids are commonly used as antiresorptive agents for the treatment of osteoporosis. Methylenediphosphonic Acid (MDP) is cheap, stable and the simplest organic bisphosphonic acid with usefulness in a wide range of applications, such as a coordination ligand of inorganic meterials ${ }^{22}$, a bone imaging agent to delineate areas of altered osteogenesis in clinic ${ }^{23}$ and a heavy-metal decorporating agents ${ }^{24}$. Due to its unique physical and chemical properties such as acidity, selectivity, thermal stability, solubility and security, we have explored its catalytic activity and discovered it can catalyze acetylation of alcohols, phenols and amines very efficiently. Here we report a mild, efficient and environmentally friendly method for the acetylation of alcohols, phenols and amines using acetic anhydride in the presence of MDP under solvent-free conditions at room temperature. The catalyst was reused five consecutive times giving excellent yields.

\section{EXPERIMENTAL}

All commercial chemicals were used as received. Methylenediphosphonic Acid (MDP) was provided by Jiangyuan Pharmaceutical Factory. Products are all known compounds and their structures were established through IR, MS and ${ }^{1} \mathrm{H}$ NMR by comparing of their physical and spectra data with those in the literature. IR spectra were recorded on BRUKER TENSOR $27 \mathrm{FT}$ IR spectrometer using $\mathrm{KBr}$ pellets. Mass spectra were recorded on a Waters Q-TOF-MS apparatus. 1H NMR spectra were run on a BRUKER AVAVCE 400 spectrometer using $\mathrm{CDCl}_{3}$ or $\mathrm{DMSO}-\mathrm{D}_{6}$ as solvent.

General Procedure of Acetylation Reaction

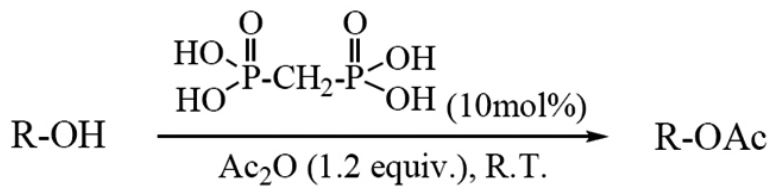

Scheme 1: Acetylation of Alcohols and Phenols

Method A: Alcohol (2.5 mmol), MDP (0.25 mmol) and $\mathrm{Ac}_{2} \mathrm{O}(3.0 \mathrm{~m} \mathrm{~mol})$ were added and stirred continued at room temperature for the appropriate time (monitored by TLC). After completion, the reactant was filtered and water $(10 \mathrm{~mL})$ was added to the filtrate. The mixture was extracted with ethyl acetate $(10 \mathrm{~mL} \times 2)$ and the combined organic layer was washed with saturated $\mathrm{NaHCO}_{3}$ $(10 \mathrm{~mL} \times 2)$, brine $(10 \mathrm{~mL})$, dried $\left(\mathrm{Na}_{2} \mathrm{SO}_{4}\right)$ and concentrated to give the pure liquid product (Scheme 1).

Method B: Alcohol $(2.5 \mathrm{mmol}), \mathrm{MDP}(0.25 \mathrm{mmol})$ and $\mathrm{Ac}_{2} \mathrm{O}(3.0 \mathrm{mmol})$ were added and stirred continued at room temperature for the appropriate time (monitored by TLC). After completion, the reactant was quenched with cold water $(10 \mathrm{~mL})$. The mixture was filtered to give the pure solid product.

Chemoselective $\mathrm{N}$-acetylation of bifunctional substrates using MDP

The substrate containing $-\mathrm{NH}_{2}$ and $-\mathrm{OH}$ groups $(2.5 \mathrm{mmol})$ was treated with $\mathrm{Ac}_{2} \mathrm{O}(2.5 \mathrm{mmol})$ in the presence of $\mathrm{MDP}(0.25 \mathrm{~mol})$ under neat conditions at room temperature. After the end of the reaction, the reactant was quenched with cold water and extracted with ethyl acetate. To concentrate the organic layer, the product was obtained without further purification.

Reuse and Recycling of the Catalyst

The reuse and recycling properties of the catalysts were tested by acetylation of 2-phenylethanol. MDP was filtered from the reaction mixture, reused to catalyse the next reaction without any treatment.

\section{RESULTS AND DISCUSSION}

Several examples illustrating the novel and rapid procedure for acetylation of alcohols, phenols and amines are presented in Table 1. The reaction conditions were standardised after conducting the acetylation of 2-phenylethanol with $\mathrm{Ac}_{2} \mathrm{O}$ using various amounts of MDP at room temperature without any solvent (entries 4, Table 1). The acetylation of 2-phenylethanol with 1.2 equiv. of $\mathrm{Ac}_{2} \mathrm{O}$ in presence of $1,2.5,5,10 \mathrm{~mol} \% \mathrm{MDP}$ afforded $24,43,67,97 \%$ yields in $2 \mathrm{~h}$ respectively, while $5 \%$ yield was obtained without MDP at the same reaction conditions. Encouraged by the success of this reaction, various primary, secondary and tertiary alcohols, phenols and amine were subjected to acetylation. Several primary and secondary alcohols underwent the acetylation reactions in excellent yields (entries 1-8, Table 1). It is very interesting to note that tertiary alcohols such as $t$-butanol and 2-methyl-2-butanol (entries 9 and 10 , Table 1) can also be acetylated with satisfactory yields and there was no elimination product in the mixture 
Table 1. Acetylation of alcohols, phenols and amines catalysed by MDP.

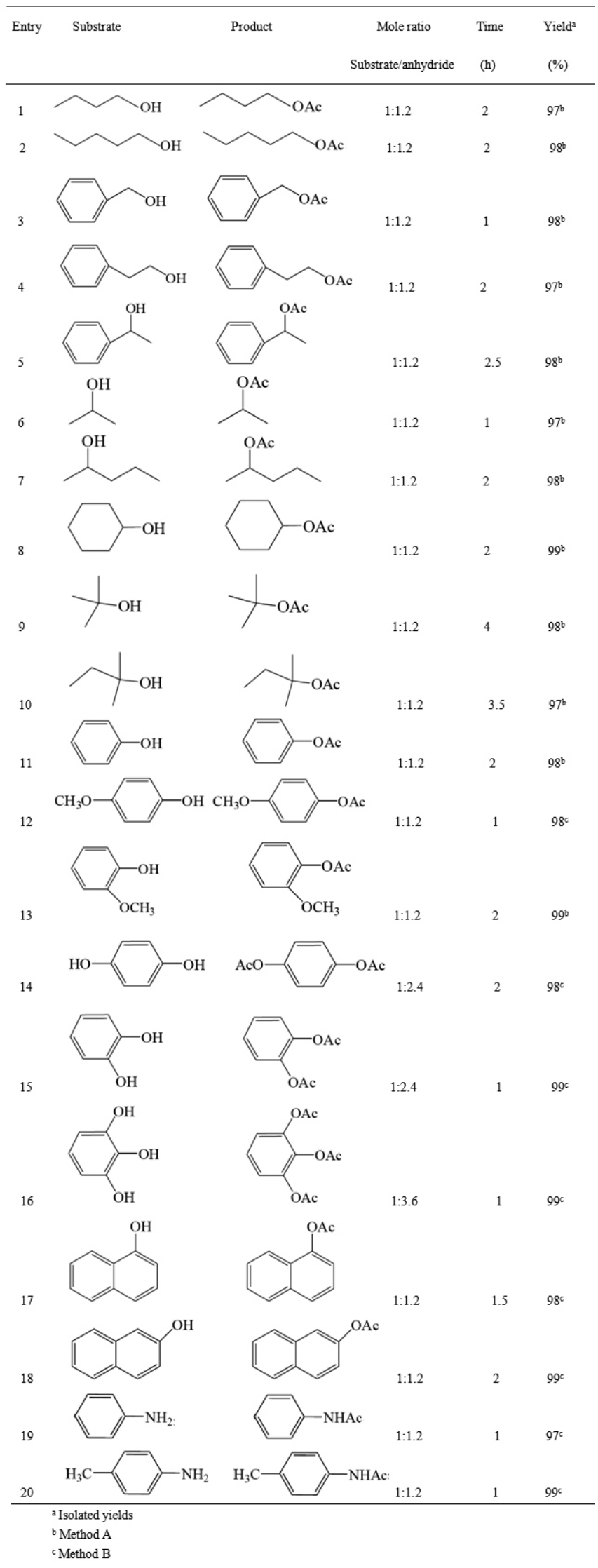

as shown by IR, MS and ${ }^{1} \mathrm{H}$ NMR analysis, the yield of entry 9 is $98 \%$, however, it is $70 \%$ using $\mathrm{Gd}(\mathrm{OTf})_{3}$ as a catalyst ${ }^{25}$. Phenols are acetylated smoothly without any side products observed (entries 11-18, Table 1). We found that this method was also suitable for the acetylation of amines and they were converted to their corresponding acetamides respectively in excellent yields (entries 19 and 20, Table 1).

Table 2. Chemoselective N-acetylation of bifunctional substrates using MDPa.

Entry

${ }^{b}$ Isolated yields

To expand the scope of the present reaction further, we performed a new study in which the selective acetylation of the bifunctional substrates containing $-\mathrm{NH}_{2}$ and $-\mathrm{OH}$ groups using our catalyst under solvent-free conditions. The results are collected in Table 2 . Only $\mathrm{N}$-acetate product was obtained with one equivalent of acetic anhydride and no $\mathrm{O}$-acetate product was discovered under these conditions. The hydroxy group of the substrates did not take part in the acetylation because $-\mathrm{NH}_{2}$ group has more nucleophilicity than -OH group. MDP could be easily recycled, it was utilized repeatedly over five times in acetylation of 2-phenylethanol with the yield being unchanged (Table 3).

Table 3: Recycling of MDP in the acetylation of 2-phenylethanol.

\begin{tabular}{|ccc|}
\hline Run & Time/h & Yield $^{\mathrm{a}}(\%)$ \\
\hline 1 & 2 & 97 \\
2 & 2 & 98 \\
3 & 2 & 96 \\
4 & 2 & 98 \\
5 & 2 & 98 \\
\hline
\end{tabular}

${ }^{\mathrm{a}}$ Isolated yields

\section{CONCLUSION}

In conclusion, MDP is an efficient catalyst for the acetylation of various alcohols, phenols and amines under solvent-free conditions. The advantages include low cost, high yields, cleaner products, selective acetylation of bifunctional compounds containing $-\mathrm{NH}_{2}$ and $-\mathrm{OH}$ groups, ease of operation, and with increasing environmental concern, absence of organic solvents and no need for energy in the present method will make it environment friendly and promising in practical production.

\section{ACKNOWLEDGMENTS}

We acknowledge financial support by the Social Development Foundation of Jiangsu (grant No. BE2008633) and the Medical Research Project of Jiangsu (grant No.H200736). 


\section{REFERENCES}

1. A.S. Frannklin, J. Chem. Soc. Perkin Trans 1, 3537, (1999).

2. R.C. Larock, "Comprehensive Organic Transformations", VCH, New York, 1989.

3. E. Vedejs, N.S. Bennett, L.M. Conn, S.T. Diver, M. Gingras, J. Org. Chem. 58, 7286, (1993); E. Vedejs, S.T. Diver, J. Am. Chem. Soc. 115, 3358, (1993).

4. K. Ishihara, M. Kubota, H. Kurihara, H. Yamamoto, J. Am. Chem. Soc. 117, 4413, (1995).

5. P.A. Procopiou, S.P.D. Baugh, S.S. Flack, G.G.A. Inglis, J. Org. Chem. 63, 2342, (1998).

6. K. Ishihara, M. Kubota, H. Yamamoto, Synlett 2, 265, (1996).

7. P. Saravanan, V.K. Singh, Tetrahedron Lett. 40, 2611, (1999).

8. K.K. Chauhan, C.G. Frost, I. Love, D. Waite, Synlett 2, 174, (1999).

9. A. Orita, C. Tanahashi, A. Kakuda, J. Otera, J. Org. Chem. 66, 8926, (2001).

10. M. Moghadam, S. Tangestaninejad, V. Mirkhani, I. MohammadpoorBaltork, M. Babaghanbari, M. Zarea, L. Shariati, S.A. Taghavi, J. Iran. Chem. Soc. 6, 523, (2009).
11. A.C. Cope, E.C. Herrich, Org. Synth. Coll 4, 304, (1963).

12. R. Kumareswaran, K. Pachamuthu, Y.D. Vankar, Synlett 11, 1652, (2000).

13. X.A. Li, T.S. Li, T.H. Ding, Chem. Commun. 5, 1389, (1997).

14. P. Kumar, K.R. Pandey, S.M. Bodas, K.M. Dongare, Synlett 2, 206, (2001).

15. B. Karimi, H. Seradji, Synlett 4, 519, (2001).

16. R. Ballini, G. Bosica, S. Carloni, L. Ciaralli, R. Maggi, G. Sartori, Tetrahedron Lett. 39, 6049, (1998).

17. R.H. Tale, R.N. Adude, Tetrahedron Lett. 47, 7263, (2006)

18. R.T. Srikanth, M. Narasimhulu, N. Suryakiran, M.K. Chinni, K. Ashalatha, Y. Venkateswarlu, Tetrahedron Lett. 47, 6825, (2006).

19. R.S. Jitendra, V. Radha, J. Catal. Commun. 9, 2365, (2008).

20. S. Farhadi, M. Taherimehr, Acta Chimi. Slov. 55, 637, (2008).

21. J.W.J. Bosco, A. Agrahari, A.K. Saikia, Tetrahedron Lett. 47, 4065, (2006).

22. G. Qiuming, G. Nathalie, N. Marc, K.C. Anthony, Chem. Mater. 11, 2937 , (1999).

23. B. David, D. Antigoni, V.M. Ralph, D. David, F. Glenn, Cancer Biother Radio 20, 189, (2005).

24. S. Fukuda, H. Iida, Y. Yan, Y. Xie, W. Chen, Health Phys. 76, 489, (1999).

25. A. Ramesh, P. Meher, S. Sampak, R. Prakash, J. Mol. Catal. A Chem 226, $57,(2005)$ 